\title{
Polybrominated diphenyl ethers, polychlorinated biphenyls and organochlorine pesticides in sediment cores from the Western Scheldt river (Belgium): analytical aspects and depth profiles
}

\author{
A. Covaci, ${ }^{a, *}$, A. Gheorghe ${ }^{b}$, S. Voorspoels ${ }^{a}$, J. Maervoet ${ }^{a}$, \\ E. Steen Redeker ${ }^{c}, R$. Blust ${ }^{c}$, P. Schepens ${ }^{a}$ \\ ${ }^{a}$ Toxicological Centre, University of Antwerp, Universiteitsplein 1, 2610 Wilrijk, Belgium \\ ${ }^{b}$ Department of Analytical Chemistry, Faculty of Chemistry, University of Bucharest, Soseaua Panduri 90-92, Bucharest, Romania \\ 'Laboratory of Ecophysiolog, Biochemistry and Toxicology. University of Antwerp, Groenenborgerlaan 171, 2020 Antwerp, Belgium
}

Received 1 July 2004; accepted 24 August 2004

Available online 1 October 2004

\begin{abstract}
A rapid and simple analytical method for the determination of organochlorines, such as polychlorinated biphenyls (PCBs) and selected organochlorinated pesticides (OCPs) and organobromines, such as polybrominated diphenyl ethers (PBDEs), in sediment samples was optimised using CRM 536 (PCBs in freshwater sediment). The method involved a hot Soxhlet extraction that reduced the extraction time to 2 h. Elemental sulphur, which is present in sediments and may interfere during the analysis, was removed by means of copper powder added to the sediment during extraction and into the clean-up cartridge. The analysis of PCBs and OCPs was accomplished by gas chromatography with electron capture or mass spectrometric detection. Similar quantitative results for PCB congeners in CRM 536 were obtained using a 50$\mathrm{m}$ capillary column and a 10-m narrow bore column suited for fast analysis. The analysis of PBDEs was done by mass spectrometry in negative chemical ionisation mode.

Concentrations of organic pollutants in two sediment cores (approximately $50 \mathrm{~cm}$ depth) from the Scheldt river (south of Antwerp, Belgium) showed a relative steady state for PCBs and DDTs, with a slight decrease in the top layers, suggesting a slight decline in their concentrations due to restrictions in their usage. On the contrary, PBDEs were showing an increase in their concentrations in the top layers (up to 270 and $8400 \mathrm{ng} / \mathrm{g}$ dry weight for sum of tri- to hexa-BDE congeners and for BDE 209, respectively). This suggests an increasing trend in the concentrations of PBDEs in the Belgian environment.
\end{abstract}

(C) 2004 Elsevier Ltd. All rights reserved.

Keywords: Sediment core; Scheldt river; PBDEs; PCBs; OCPs; Method optimisation

\section{Introduction}

Despite their ban or restricted use (UNEP, 2003), polychlorinated biphenyls (PCBs) and organochlorine pesticides (OCPs) are among the most prevalent environmental pollutants and can be found in various environmental compartments, as well abiotic (air, water, sediments, soil) (de Boer et al., 2001) as biotic (from

\footnotetext{
* Corresponding author. Fax: +323820 2722 .

E-mail address: adrian.covaci@ua.ac.be (A. Covaci).
}

plankton to humans) (de Boer et al., 2000; de Voogt et al., 1990; Jones and de Voogt, 1999).

In contrast to PCBs, the use and production of polybrominated diphenyl ethers (PBDEs) is still being continued, although recently some restrictions have been issued following risk assessment reports (EU, 2003). PBDEs are used as flame retardants to improve fire safety in both commercial and domestic applications, where they are sometimes added in concentrations up to $30 \%$ by weight (WHO, 1994). These chemicals have shown a rise in production since they were first introduced in the $1960 \mathrm{~s}$, with a substantial increase since the end of the 1970 s due to 
the growing popularity of personal computers and other electronic equipment (de Boer et al., 2000). Unfortunately, this has lead to their widespread presence in various environmental compartments (de Boer et al., 2001; de Wit, 2002; Ikonomou et al., 2002; Law et al., 2003).

Sediments, particularly estuarine sediments, are one of the major sinks for these contaminants in the aquatic environment (Allchin et al., 1999; de Boer et al., 2001; Voorspoels et al., 2004). The study of sediments is an important step in mapping possible exposure pathways to various aquatic organisms, since contaminants in the sediments may be bioavailable to sediment dwelling organisms (Pruell et al., 1993). Furthermore, dated sediment profiles have been used to estimate the historical deposition of PCBs and other organic pollutants in the river bed impacted by local and regional sources (Fox et al., 2001).

The drainage basin of the Scheldt river covers a very densely populated and highly industrialised area of northern France, western Belgium and the southwestern Netherlands (Baeyens et al., 1998), resulting in a high pollution level with POPs (Voorspoels et al., 2003, 2004), as well as heavy metals (Coteur et al., 2003). High concentrations of PBDEs (up to $500 \mathrm{ng} / \mathrm{g} \mathrm{dw}$ for BDE 209) were already measured in sediment samples from the Scheldt river (de Wit, 2002), while de Boer et al. (2003) have reported high levels of BDE 209 (up to $4600 \mathrm{ng} / \mathrm{g}$ dry weight) in suspended particulate matter (SPM) from the Western Scheldt and attribute this to spillage during use further upstream.

The scope of this work was (1) to optimise a rapid and simple analytical method for the determination of organochlorinated and organobrominated pollutants in sediments and (2) to measure the concentrations of organic pollutants in two sediment cores $(\sim 50 \mathrm{~cm})$ from the Scheldt river, near Antwerp, Belgium and to evaluate temporal trends in pollution of PCBs, OCPs and PBDEs.

\section{Materials and methods}

\subsection{Samples}

Sediment cores $(\sim 50 \mathrm{~cm})$ were taken in March 2000 with a 2-cm-diameter gravity corer from two locations situated in the Scheldt river (near Kruibeke, south of Antwerp, Belgium) from zones with different flow characteristics. The two locations (A and B) were located within $100 \mathrm{~m}$ from each other. Subsamples were obtained by slicing the core in 1-5 cm intervals. Wet sediments were kept at $+4{ }^{\circ} \mathrm{C}$ until further treatment. Prior to analysis, sediments were dried at room temperature for $48 \mathrm{~h}$.

\subsection{Reagents and standards}

The following compounds were included: hexachlorobenzene $(\mathrm{HCB}), \alpha-, \beta$ - and $\gamma$-hexachlorocyclohexane
(HCH) isomers (the sum expressed as $\mathrm{HCHs}$ ), $p, p^{\prime}-\mathrm{DDE}$, $p, p^{\prime}$-DDD, and $p, p^{\prime}$-DDT (the sum expressed as DDTs) and 27 PCB congeners (IUPAC nos.: 18, 28, 31, 44, 52, 74, 95, $99,101,105,110,118,128,132,138,149,153,156,163$, $170,177,180,183,187,194,196$ and 199). PCBs 46 and 143 were used as internal standard (IS) for PCBs and pesticides. Additionally, $10 \mathrm{PBDE}$ congeners were also measured and polybrominated biphenyl (PBB) 103 was used as IS for BDE $28,47,66,85,99$ and $100, \mathrm{BB} 155$ was used as IS for BDE 138,153 and 154 , while ${ }^{13} \mathrm{C}$-labeled BDE 209 was used as IS for BDE 209.

All solvents used for the analyses ( $n$-hexane, acetone, dichloromethane and iso-octane) were of SupraSolv grade (Merck, Darmstadt, Germany). Individual analytical standards (CIL, Andover, MA, USA; Dr. Ehrenstorfer Laboratories, Augsburg, Germany) were used for identification and quantification. A certified material (CRM 536-PCBs in freshwater sediment-IRMM, Geel, Belgium) was used for the method optimisation.

\subsection{Extraction and clean-up}

The sediment sample (around $1 \mathrm{~g}$ ) was placed into a hexane pre-washed extraction thimble. A triple amount of copper powder ( $<63 \mu \mathrm{m}$, Merck) was added and mixed with the sediment, followed by the addition of internal standards. Samples were extracted using a Soxhlet extractor B-811 (Büchi, Switzerland) operated in hot extraction mode. Several solvent mixtures $(75 \mathrm{ml})$, such as hexane/acetone $(3: 1, v / v)$, hexane/acetone $(1: 1, v / v)$ and hexane/dichloromethane $(3: 1, v / v)$ were tested for different extraction times (2, 3 and $4 \mathrm{~h})$. In each case, the extract was concentrated and transferred onto a solid-phase extraction (SPE) cartridge filled (from the bottom) with 8 $\mathrm{g}$ acidified silica ( $40 \%$ concentrated sulphuric acid, w/w), $0.5 \mathrm{~g}$ anhydrous sodium sulphate and $1 \mathrm{~g}$ copper powder. The elution of PCBs, OCPs and PBDEs was done with 15 $\mathrm{ml}$ hexane and $10 \mathrm{ml}$ DCM. The eluate was concentrated to near dryness by a rotary evaporator and further by a gentle nitrogen stream. The final extract was re-solubilized in $80 \mu \mathrm{l}$ iso-octane.

\subsection{Instrumental analysis}

The determination of PCBs and OCPs was performed by gas chromatography with electron capture detection (GC-ECD). An Agilent (Palo Alto, CA, USA) 6890 GC$\mu E C D$ was equipped with a $50 \mathrm{~m} \times 0.22 \mathrm{~mm} \times 0.25 \mu \mathrm{m}$ HT-8 capillary column (SGE, Zulte, Belgium). Helium was used as carrier gas at a constant flow of $1.0 \mathrm{ml} / \mathrm{min}$ and $\mathrm{Ar} / \mathrm{CH}_{4}$ (95:5) was used as make-up gas (40 ml/min). One microliter was injected in the pulsed splitless mode (pulse pressure $=40 \mathrm{psi}$, pulse time $=1.2 \mathrm{~min}$ ) with the split outlet opened after $1.2 \mathrm{~min}$. Injector and detector temperatures were set at 290 and $320{ }^{\circ} \mathrm{C}$, respectively. The temperature program of the HT- 8 column was set to $90{ }^{\circ} \mathrm{C}$ 
for $1.2 \mathrm{~min}$, then increased with $20^{\circ} \mathrm{C} / \mathrm{min}$ to $180{ }^{\circ} \mathrm{C}$, kept for $1 \mathrm{~min}$, then increased with $3{ }^{\circ} \mathrm{C} / \mathrm{min}$ to $275^{\circ} \mathrm{C}$, kept $0.5 \mathrm{~min}$ and further ramped by $5{ }^{\circ} \mathrm{C} / \mathrm{min}$ to $290{ }^{\circ} \mathrm{C}$ and kept for $18 \mathrm{~min}$.

Additionally, an Agilent 6890GC-5793 quadrupole mass spectrometer (MS) equipped with a $10 \mathrm{~m} \times 0.10$ $\mathrm{mm} \times 0.10 \mu \mathrm{m}$ HT- 8 narrow bore capillary column was tested for its ability of performing fast analysis of PCBs. The oven program started from $90{ }^{\circ} \mathrm{C}$, for $1 \mathrm{~min}$, then increased with $50^{\circ} \mathrm{C} / \mathrm{min}$ to $200^{\circ} \mathrm{C}$, kept for $0.5 \mathrm{~min}$, then increased with $25^{\circ} \mathrm{C} / \mathrm{min}$ to $250^{\circ} \mathrm{C}$, kept for $0.2 \mathrm{~min}$ and finally ramped by $75{ }^{\circ} \mathrm{C} / \mathrm{min}$ to $300^{\circ} \mathrm{C}$ and kept $5 \mathrm{~min}$. Total analysis time was $11 \mathrm{~min}$. Helium was used as carrier gas at $0.4 \mathrm{ml} / \mathrm{min}$. The MS was operated at $70 \mathrm{eV}$ in electron impact ionisation (EI) mode with ion source, quadrupole and transfer line temperatures of 230,150 and $300{ }^{\circ} \mathrm{C}$, respectively. Dwell times were set to $10 \mathrm{~ms}$ and two ions from the molecular ion cluster of each PCB homologue group $\left(\mathrm{M}^{+}\right.$and $\left.[\mathrm{M}+2]^{+}\right)$were monitored. The relative retention times to the nearest internal standard and ratios between the monitored ions were used as identification criteria. A deviation of ion ratios of less than $\pm 20 \%$ from the theoretical value was considered acceptable for identification.

The determination of PBDEs was performed with an Agilent $6890 \mathrm{GC}-5973 \mathrm{MS}$ equipped with a $25 \mathrm{~m} \times 0.22$ $\mathrm{mm} \times 0.25 \mu \mathrm{m}$ HT- 8 capillary column and operated in electron capture negative ionisation (ECNI) mode. The ion source, quadrupole and interface temperatures were 250 , 150 and $300{ }^{\circ} \mathrm{C}$, respectively. Helium was used as carrier gas at constant flow $(1.0 \mathrm{ml} / \mathrm{min})$ with an initial pressure of $14.40 \mathrm{psi}$ and with methane as moderating gas. The MS was operated in the selected ion monitoring (SIM) mode and the electron multiplier voltage was set at $2100 \mathrm{~V}$. One microliter of the extract was injected in solvent vent mode (injector temperature at $90^{\circ} \mathrm{C}$, kept for $0.05 \mathrm{~min}$, then increased with $700{ }^{\circ} \mathrm{C} / \mathrm{min}$ to $280^{\circ} \mathrm{C}$, vent time $0.03 \mathrm{~min}$, vent flow 100 $\mathrm{ml} / \mathrm{min}$ ). The splitless time was $1.50 \mathrm{~min}$. The temperature of the HT- 8 column was programmed from $90^{\circ} \mathrm{C}$, kept for $1.5 \mathrm{~min}$, then increased with $30^{\circ} \mathrm{C} / \mathrm{min}$ to $180^{\circ} \mathrm{C}$, kept for $0.5 \mathrm{~min}$, then increased with $5^{\circ} \mathrm{C} / \mathrm{min}$ to $270^{\circ} \mathrm{C}$, kept for $0.5 \mathrm{~min}$ and finally ramped with $25^{\circ} \mathrm{C} / \mathrm{min}$ to $290^{\circ} \mathrm{C}$ and $\mathrm{kept}$ for $15 \mathrm{~min}$. Dwell times were set to $25 \mathrm{~ms}$. Ions $\mathrm{m} / \mathrm{z} 79$ and 81 were monitored for the entire run.

The analysis of BDE 209 was performed on a $12 \mathrm{~m} \times 0.18$ $\mathrm{mm} \times 0.10 \mu \mathrm{m}$ AT- 5 capillary column (Alltech, Lokeren, Belgium). Helium was used as carrier gas at an initial flow rate of $1.0 \mathrm{ml} / \mathrm{min}$ (kept for $5 \mathrm{~min}$ ) and then raised to $1.5 \mathrm{ml} /$ $\mathrm{min}$ at $20 \mathrm{ml} / \mathrm{min}^{2}$. The oven temperature program started from $90{ }^{\circ} \mathrm{C}$, kept for $1.35 \mathrm{~min}$, and then increased with 25 ${ }^{\circ} \mathrm{C} / \mathrm{min}$ to $290^{\circ} \mathrm{C}$, kept for $8 \mathrm{~min}$. Methane was used as moderating gas and the ion source, quadrupole, and interface temperatures were 250,150 and $300{ }^{\circ} \mathrm{C}$, respectively. Dwell time was set to $50 \mathrm{~ms}$. The ECNI-MS was operated in SIM mode at the $\mathrm{m} / \mathrm{z} 484.7,486.7$ and $494.7,496.7$ for BDE 209 and ${ }^{13} \mathrm{C}$-BDE 209, respectively.

\subsection{Quality control}

Quality for PCB and OCP analyses was assured through the analysis of procedural blanks, blind duplicate samples and certified material (CRM 536-PCBs in freshwater sediment). The obtained values for PCB congeners in CRM 536 were all within $10 \%$ of the certified values.

For PBDEs, an in-house reference material (a sediment sample used for the BROC interlaboratory feasibility study-BROC, 2003) was used for method validation. The concentrations of individual PBDE congeners did not differ with more than $15 \%$ from the mean values obtained in the BROC study (BROC, 2003). Recoveries of individual PBDE congeners, including BDE 209, obtained during BROC spiking experiments (BROC, 2003) are between $82 \%$ and $93 \%$ with a standard deviation less than $16 \%$.

The limit of quantification (LOQ) for PCBs, OCPs and PBDEs was based on GC/ECD and GC/MS performance and on laboratory background levels, which were determined by analysing procedural blanks. Procedural blank levels were consistent $(\mathrm{RSD}<30 \%)$ and therefore the median blank value was used for subtraction. LOQs were established at three times the standard deviation of the procedural blank level, resulting in a certainty of more than $95 \%$ for results given for the samples. LOQs for PCBs and OCPs ranged between 0.1 and $0.4 \mathrm{ng} / \mathrm{g}$ when $1 \mathrm{~g}$ of sediment was analysed. Recoveries of internal standards were between $86 \%$ and $92 \%$ (RSD $<9 \%$ ). LOQs for tri- to hexa-PBDEs ranged between 0.05 and $0.1 \mathrm{ng} / \mathrm{g} \mathrm{dw}$, while for BDE 209 LOQ was $0.2 \mathrm{ng} / \mathrm{g} \mathrm{dw}$.

Additionally, the Toxicological Centre (University of Antwerp-UA, Belgium) has participated to several interlaboratory studies for PCBs, OCPs and PBDEs organised through the Quasimeme office. Sediment samples analysed for PCBs and OCPs (Table 1) and PBDEs (Table 2) showed good agreement between values obtained by UA and mean values of participating laboratories.

Table 1

Concentrations (ng/g dw) of PCBs and OCPs in two sediment samples (68MS and 69MS) used in the QUASIMEME 2002 interlaboratory test (UA-results of Toxicological Center, University of Antwerp versus mean of participating laboratories)

\begin{tabular}{llllll}
\hline & $68 \mathrm{MS}$ & & & $69 \mathrm{MS}$ & \\
\cline { 2 - 3 } & $\mathrm{UA}$ & mean & & UA & mean \\
\hline PCB 28 & 0.20 & 0.21 & 1.30 & 0.90 \\
PCB 101 & 0.50 & 0.56 & & 1.10 & 1.37 \\
PCB 105 & 0.18 & 0.17 & 0.53 & 0.44 \\
PCB 118 & 0.48 & 0.43 & 1.30 & 1.36 \\
PCB 138 & 1.15 & 1.23 & 2.65 & 2.71 \\
PCB 153 & 1.28 & 1.21 & 2.98 & 2.71 \\
PCB 180 & 0.87 & 0.72 & 1.59 & 1.59 \\
$p, p^{\prime}$-DDE & 0.78 & 0.65 & 0.66 & 0.59 \\
$p, p^{\prime}$-DDT & 0.37 & 0.30 & 0.76 & 0.41 \\
HCB & 0.17 & 0.11 & 1.36 & 0.94 \\
\hline
\end{tabular}


Table 2

Concentrations (ng/g dw) of PBDEs in three sediment samples (1MS, 3MS and BROC) used in the QUASIMEME 2002 and 2003 interlaboratory tests (UA - results of Toxicological Center, University of Antwerp versus the mean of participating laboratories)

\begin{tabular}{|c|c|c|c|c|c|c|}
\hline & \multicolumn{2}{|l|}{$1 \mathrm{MS}$} & \multicolumn{2}{|l|}{$3 \mathrm{MS}$} & \multicolumn{2}{|l|}{ BROC } \\
\hline & UA & Mean & UA & Mean & UA & Mean \\
\hline BDE 28 & 0.43 & 0.54 & 0.13 & 0.13 & 0.75 & 0.626 \\
\hline BDE 47 & 9.64 & 8.93 & 0.93 & 0.96 & 10.20 & 10.14 \\
\hline BDE 99 & 12.71 & 13.18 & 0.98 & 1.05 & 12.29 & 14.20 \\
\hline BDE 100 & 3.00 & 2.65 & 0.11 & 0.12 & 2.90 & 3.04 \\
\hline BDE 153 & 2.31 & 1.80 & 0.23 & 0.21 & 1.85 & 1.93 \\
\hline BDE 154 & 1.89 & 1.64 & 0.11 & 0.11 & 1.59 & 1.71 \\
\hline BDE 183 & 1.01 & 0.32 & 0.18 & 0.14 & 0.75 & 0.45 \\
\hline BDE 209 & 920 & 863 & 47.0 & 45.2 & 1234 & 1163 \\
\hline
\end{tabular}

\subsection{Statistical analysis}

Statistical analysis was performed with SPSS 12.0 statistical software (Chicago, IL, US). The influence of extraction time and solvent mixtures on the recovery of PCBs from CRM 536 was analysed with univariate analysis of variance (ANOVA) using general linear model and Scheffe test for post hoc comparison. Values were considered significantly different when $p<0.05$.

Principal components analysis (PCA) was performed with Statistical software Minitab Version 14.10 (Minitab Quality Plaza, 1829 Pine Hall Road, State College, PA 16801-3008, USA) using the correlation matrix. Results have been graphically displayed as score plot and loading plot.

\section{Results and discussion}

\subsection{Method optimisation}

The method described in the present paper was adapted from a previously described method for the extraction of organohalogenated pollutants from soils (Covaci et al., 2002).
For method optimisation, a certified material CRM 536 (PCBs in freshwater harbour sediment) was used and concentrations obtained during different method setups were compared with the certified values. For extraction, an automated Soxhlet was used in hot extraction mode, where the sample is permanently in contact with hot, but nonboiling solvent. No significant differences were observed between the PCB concentrations obtained from the certified material CRM 536 for different extraction times ( 2,3 and $4 \mathrm{~h}$, respectively), allowing thus a dramatic reduction in the extraction time compared with the $8-16 \mathrm{~h}$ usually needed for classical Soxhlet extraction (Smedes and de Boer, 1997).

Several solvent mixtures were tested for the extraction efficiency and it has been found that the mixtures hexane/ acetone $(3: 1, \mathrm{v} / \mathrm{v})$ and hexane/acetone $(1: 1, \mathrm{v} / \mathrm{v})$ gave similar recoveries for the certified $\mathrm{PCBs}$, while the use of a mixture hexane/dichloromethane $(3: 1, \mathrm{v} / \mathrm{v})$ resulted in significantly lower values (Fig. 1). In order to increase the extraction efficiency, it is necessary to use a more polar solvent, such as acetone, which can penetrate the more polar core of sediment particles. A similar observation has already been reported for soil (Covaci et al., 2002). The hexane/acetone $(3: 1, v / v)$ mixture was preferred because the lower percentage of acetone in the extraction mixture results in a final raw extract free of acetone, which is necessary for clean-up on acidified silica.

The sulphur originates under anaerobic conditions from microbial sulphate reduction (via sulphide) and the degradation of organic sulphur compounds (Riis and Babel, 1999). Smedes and de Boer (1997) have shown that the presence of elemental sulphur in the finale extract prior to $\mathrm{GC}$ analysis may have a bad effect on the performance of the ECD detector and on the correct peak assignment. For sulphur elimination, copper powder was added in the extraction thimble and on the top of the acidified silica gel cartridge, thus eliminating a tendentious additional step in the clean-up procedure. The sulphur removal by means of $\mathrm{Cu}$ was very efficient for all analysed samples and the

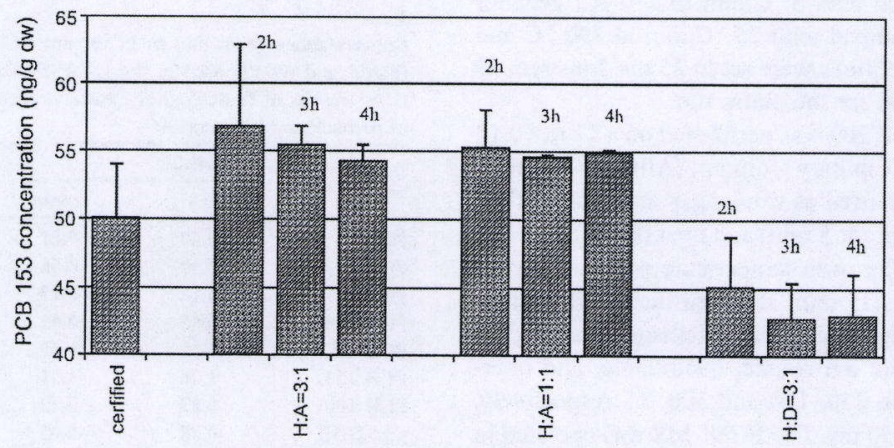

Fig. 1. Influence of extraction time and composition of extraction solvent mixture on the recovery of PCB 153 from $\mathrm{CRM} 536$ (H-hexane, A-acetone, D dichloromethane). Error bars represent $1.96 \times$ standard error. 
Table 3

Recoveries of certified PCB congeners from CRM 536

\begin{tabular}{lllr}
\hline & Certified values (S.D.) & Recovered values (S.D.) & $\%$ \\
\hline PCB 28 & $44(5)$ & $48(3)$ & 110 \\
PCB 52 & $38(4)$ & $41(2)$ & 109 \\
PCB 101 & $44(4)$ & $48(0)$ & 110 \\
PCB 105 & $3.5(0.6)$ & $3.8(0.4)$ & 110 \\
PCB 118 & $28(3)$ & $27(1)$ & 96 \\
PCB 128 & $5.4(1.2)$ & $4.6(0.5)$ & 86 \\
PCB 138 & $27(4)$ & $33(2)$ & 122 \\
PCB 149 & $49(4)$ & $52(2)$ & 118 \\
PCB 153 & $50(4)$ & $57(4)$ & 114 \\
PCB 156 & $3.0(0.4)$ & $3.6(0.2)$ & 120 \\
PCB 163 & $17(3)$ & $18(3)$ & 105 \\
PCB 170 & $13(1)$ & $13(1)$ & 96 \\
PCB 180 & $22(2)$ & $22(1)$ & 101 \\
\hline
\end{tabular}

reduction of elemental sulphur (which may be up to 7-10 $\mathrm{mg} / \mathrm{g}$ sediment) was done to a level at which it did not interfere with the GC analysis. Riis and Babel (1999) have already demonstrated that $\mathrm{Cu}$ powder reacts with elemental sulphur if the contact time is more than $30 \mathrm{~min}$. Furthermore, the use of $\mathrm{Cu}$ powder results in a higher reaction surface than in case of $\mathrm{Cu}$ granules or $\mathrm{Cu}$ wire. They have also shown that the commercially available Cu powder $(<63$ mesh, Merck) can be used directly, without any additional pretreatment. Furthermore, no adsorption of organohalogenated pollutants has been observed on the $\mathrm{Cu}$ powder during the present work, in accordance with observations by Riis and Babel (1999).

The use of acidified silica for clean-up resulted in cleaner extracts than silica or Florisil, but some OCPs, such as dieldrin, heptachlor and heptachlorepoxide, are completely destroyed by the acidic treatment. The use of basic silica $(33 \% \mathrm{KOH}, \mathrm{w} / \mathrm{w})$ in combination with acid silica might improve the extract cleanliness, but this should be applied when only PCBs and PBDEs are the target analytes. Several other OCPs, such as HCHs and DDTs, are labile in basic conditions.

Due to some co-elutions on the HT- 8 column when ECD was used (such as PCB 110/o, $p^{\prime}-\mathrm{DDD}, \mathrm{PCB} 132 / p, p^{\prime}-$ DDD, PCB 128/PCB 174, PCB 156/PCB 172), the use of a confirmatory analysis by GC/MS was mandatory. It was previously shown (Covaci and Schepens, 2001) that narrow bore capillary columns could be successfully used in the determination of PCBs by GC/MS. Therefore, a narrow bore column with a similar stationary phase as the one used in the GC/ECD was used on GC/MS. Results for the certified material CRM 536 obtained on both columns agreed satisfactory (difference less than $10 \%$ ) for PCBs which did not present co-elutions on ECD (such as PCB 118, 153, 180 ). Moreover, these concentrations (Table 3) were in agreement with the certified values $(>90 \%$ for most congeners).

\subsection{Presence of organic pollutants in sediments from the Scheldt river}

\subsubsection{Levels of pollutants}

OCP levels were low, with HCHs being below LOQ, $\mathrm{HCB}$ values between 0.5 and $1.3 \mathrm{ng} / \mathrm{g} \mathrm{dw}$ and with DDTs between 6.6 and $44.4 \mathrm{ng} / \mathrm{g} \mathrm{dw} . p, p^{\prime}$-DDE $(41 \%)$ and $p, p^{\prime}-$ DDD $(41 \%)$ were the principal contributors to the sum DDTs (Table 4) in all samples, except for A2, where $p, p^{\prime}-$ DDT was the principal component (37\%).

The PCB concentrations in the upper layers of the two sediment cores are similar to levels (up to $200 \mathrm{ng} / \mathrm{g} \mathrm{dw}$ ) obtained in 1987-1988 from Western Scheldt estuary (Van Zoest and Van Eck, 1993), showing that the PCB pollution

Table 4

Concentrations (ng/g dry weight) of organochlorinated and organobrominated pollutants in sediment cores from two locations (A and B) from the Scheldt river

\begin{tabular}{|c|c|c|c|c|c|c|c|c|c|c|c|}
\hline & $\begin{array}{l}\text { Depth } \\
(\mathrm{cm})\end{array}$ & $\begin{array}{l}\text { PCB } \\
153 \\
\end{array}$ & $\begin{array}{l}\text { Sum } \\
\text { PCBs }\end{array}$ & $\begin{array}{l}\text { Tri- to } \\
\text { hexa-BDEs }\end{array}$ & $\begin{array}{l}\text { BDE } \\
209 \\
\end{array}$ & HCB & $p, p^{\prime}-\mathrm{DDE}$ & $p, p^{\prime}$-DDD & $p, p^{\prime}$-DDT & $\begin{array}{l}\text { Sum } \\
\text { DDTs }\end{array}$ & $\begin{array}{l}\text { Sum } \\
\text { HCHs }\end{array}$ \\
\hline A1 & $0-1$ & 23.5 & 183 & 85.1 & 2842 . & 0.7 & 4.4 & 4.4 & 3.0 & 11.8 & $<0.3$ \\
\hline $\mathrm{A} 2$ & $2-3$ & 32.3 & 238 & 179 & 7412 & 1.2 & 6.7 & 6.5 & 7.9 & 21.0 & $<0.3$ \\
\hline $\mathrm{A} 3$ & $4-5$ & 22.0 & 167 & 29.7 & NA & 1.1 & 5.4 & 4.9 & 1.9 & 12.2 & $<0.3$ \\
\hline $\mathrm{A} 4$ & $6-7$ & 28.2 & 201 & 3.7 & 1736 & 1.1 & 5.5 & 5.7 & 3.1 & 14.3 & $<0.3$ \\
\hline A5 & $8-9$ & 14.8 & 105 & 2.2 & 653 & 0.3 & 3.2 & 3.2 & 0.2 & 6.6 & $<0.3$ \\
\hline A6 & $10-15$ & 24.3 & 201 & 4.8 & 401 & 1.2 & 5.1 & 5.7 & 2.4 & 13.3 & $<0.3$ \\
\hline A7 & $20-25$ & 28.9 & 235 & 32.2 & 1370 & 0.8 & 6.8 & 8.0 & 2.8 & 17.6 & $<0.3$ \\
\hline A8 & $35-40$ & 46.4 & 400 & 11.8 & 1165 & 1.1 & 11.4 & 10.9 & 5.2 & 27.6 & $<0.3$ \\
\hline A9 & $45-50$ & 23.6 & 192 & 1.4 & 332 & 0.4 & 5.2 & 4.9 & 2.6 & 12.7 & $<0.3$ \\
\hline $\mathrm{A} 10$ & $55-58$ & 38.1 & 310 & 2.9 & 913 & 1.0 & 10.0 & 8.4 & 5.0 & 23.4 & $<0.3$ \\
\hline $\mathrm{Bl}$ & $0-1$ & 27.9 & 232 & 272 & 8413 & 0.8 & 6.6 & 7.0 & 2.8 & 16.4 & $<0.3$ \\
\hline B2 & $2-3$ & 30.6 & 232 & 180 & 5580 & 1.3 & 5.9 & 5.8 & 3.1 & 14.9 & $<0.3$ \\
\hline B3 & $4-5$ & 25.8 & 206 & 171 & NA & 1.0 & 6.6 & 6.4 & 2.1 & 15.1 & $<0.3$ \\
\hline B4 & $6-7$ & 21.2 & 173 & 47.5 & NA & 0.6 & 4.9 & 5.9 & 1.5 & 12.4 & $<0.3$ \\
\hline B5 & $10-15$ & 23.4 & 198 & 4.3 & 469 & 0.7 & 5.1 & 6.6 & 1.8 & 13.4 & $<0.3$ \\
\hline B6 & $20-25$ & 19.0 & 151 & 2.0 & 315 & 0.5 & 3.8 & 4.9 & 0.8 & 9.4 & $<0.3$ \\
\hline B7 & $35-40$ & 36.6 & 311 & 1.4 & 515 & 0.8 & 8.1 & 4.1 & 3.3 & 15.6 & $<0.3$ \\
\hline B8 & $45-50$ & 26.5 & 242 & 2.5 & 668 & 0.7 & 7.2 & 7.4 & 2.3 & 16.9 & $<0.3$ \\
\hline
\end{tabular}

NA-not available due to insufficient sample. 


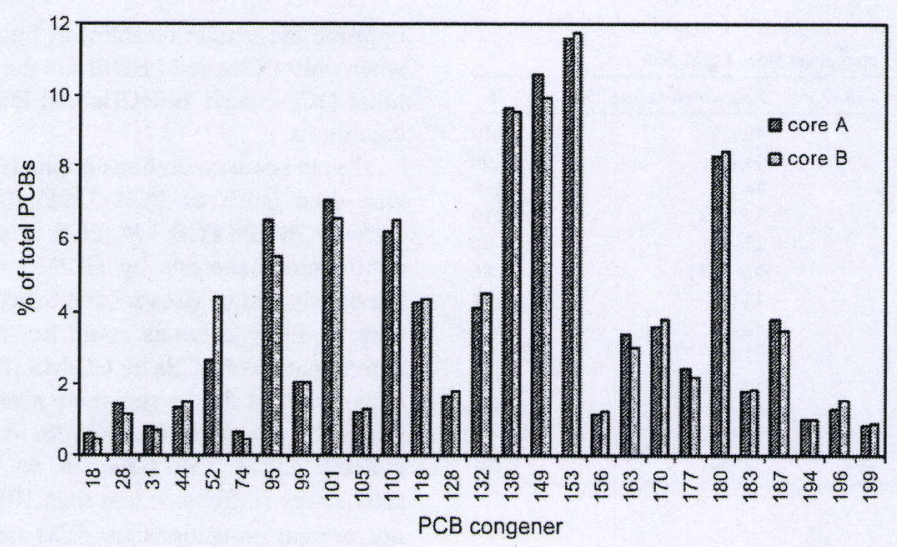

Fig. 2. Profiles of selected tri- to octa-CB congeners in two sediment cores from the Scheldt river.

has only slightly decreased in the last 15 years. This is probably due to the heavy industrialisation of the river's catchement area with continuous input of pollutants. The PCB concentrations found in the surface layers of the sediment cores were also similar to levels up to $120 \mathrm{ng} / \mathrm{g} \mathrm{dw}$ found in sediments from the Amsterdam and Rotterdam harbour (de Boer et al., 2001). The PCB congener profile was similar between the two sediment cores (Fig. 2). Concentrations of tri- and tetra-CB congeners were low, while the predominant homologues were the penta- to hepta-CBs (Fig. 2), with a profile resembling to a mixture of Aroclor 1254 and 1260.

In the present study, PBDEs were also found in the sediment layers from the Scheldt river $(1.4-270 \mathrm{ng} / \mathrm{g} \mathrm{dw}$ for the sum of tri- to hexa-BDE congeners) (Table 4). The PBDE profile in these samples (Fig. 3) was very similar to the profile of penta-BDE technical mixture (Sjödin et al., 1998). High concentrations of BDE 209 (up to $8400 \mathrm{ng} / \mathrm{g}$ $\mathrm{dw}$ ) were found also in the top layers of the cores from the present study (Table 4).

Previously, lower concentrations of tri- to hexa-BDE congeners $(32 \mathrm{ng} / \mathrm{g} \mathrm{dw})$ and BDE $209(1200 \mathrm{ng} / \mathrm{g} \mathrm{dw})$ were found in the Western Scheldt, near the Belgian-Dutch border (BROC, 2003). However, this sample was collected with a Van Veen grab sampler which mixes deeper sediment layers with surface layers. This results therefore in a "dilution" of pollutant's concentrations.

\subsubsection{Core distribution of pollutants}

The depth profiles of PCBs and DDTs were similar in the two sediment cores (depths of 58 and $50 \mathrm{~cm}$, respectively), while the concentrations of PCBs and DDTs showed a slight, but non-significant increase with the depth (Table 4). This suggests that the pollution of the Scheldt river has only slightly decreased in the past years, a phenomenon which was already reported for other polluted rivers, such as the Rhine (de Boer et al., 2001). In contrast, PCB levels in cores from marine or lake sediments show an evident decline in the past years, since their sources are mainly from fall out and atmospheric deposition (Isosaari et al., 2002).

For each sediment layer, the ratios between the levels of $p, p^{\prime}$-DDE and $p, p^{\prime}$-DDD were close to the unit $(1.01 \pm 0.10$ and $1.04 \pm 0.39$ for cores $A$ and $B$, respectively). This indicates that aerobic and anaerobic degradations of $p, p^{\prime}-$ DDT occurred at equal rates. Similar values for the ratio

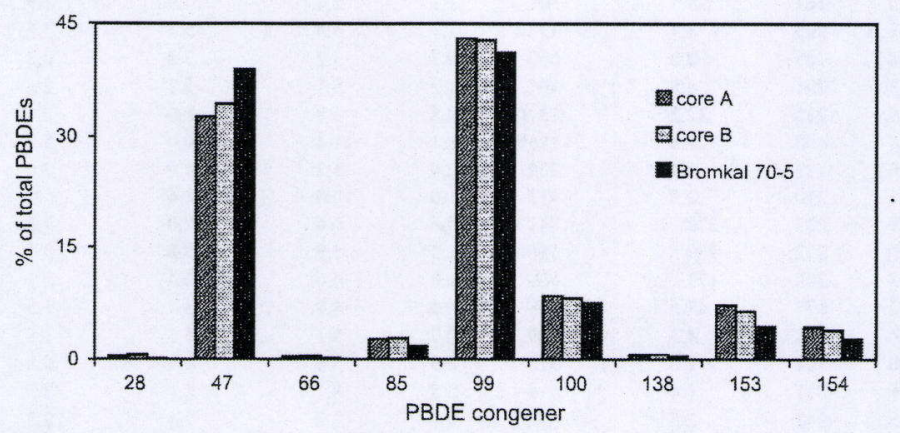

Fig. 3. Profiles of selected tri- to hexa-BDE congeners in two sediment cores from the Scheldt river and in the technical mixture Bromkal 70-5. 


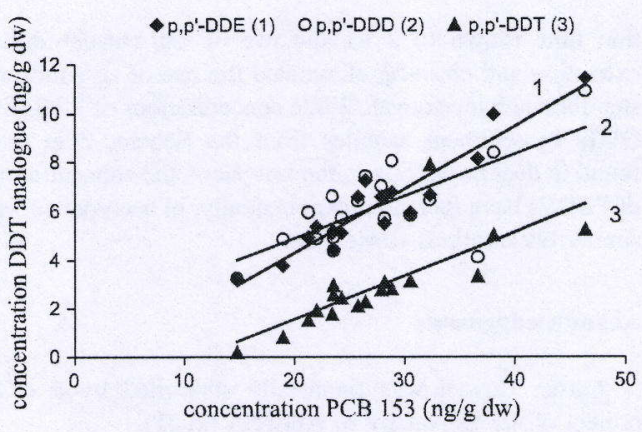

Fig. 4. Correlations between concentrations of DDTs analogues and concentration of PCB 153. ( $p, p^{\prime}-\mathrm{DDE}: y=0.259 x-0.877, R^{2}=0.894$, $p<0.001 ; p, p^{\prime}$-DDD: $y=0.172 x+1.451, R^{2}=0.514, p<0.001 ; p, p^{\prime}$-DDT: $y=0.180 x-2.048, R^{2}=0.586, p<0.001$ ). $p, p^{\prime}-\mathrm{DDE} / p, p^{\prime}-\mathrm{DDD}$ were found in bed sediment from urban sites sampled between 1992 and 2001 from United States river and streams (NAWQA, 2003).

High significant correlation coefficients were found between the concentrations of DDT analogues $\left(p, p^{\prime}-\mathrm{DDE}\right.$, $p, p^{\prime}$-DDD and $p, p^{\prime}$-DDT) and the concentration of PCB 153 (Fig. 4), suggesting a similar trends in pollution changes for the two classes of pollutants.

The depth profiles of PBDEs in the sediment cores were completely different from those of PCBs, showing a steep increase in the surface layers compared with deeper core layers (Table 4). This is in accordance with the increase in the production and use of PBDEs in the last decades and with the high PBDE levels observed in surface sediments from other PBDE-polluted rivers, such as river Tees (Allchin et al., 1999).
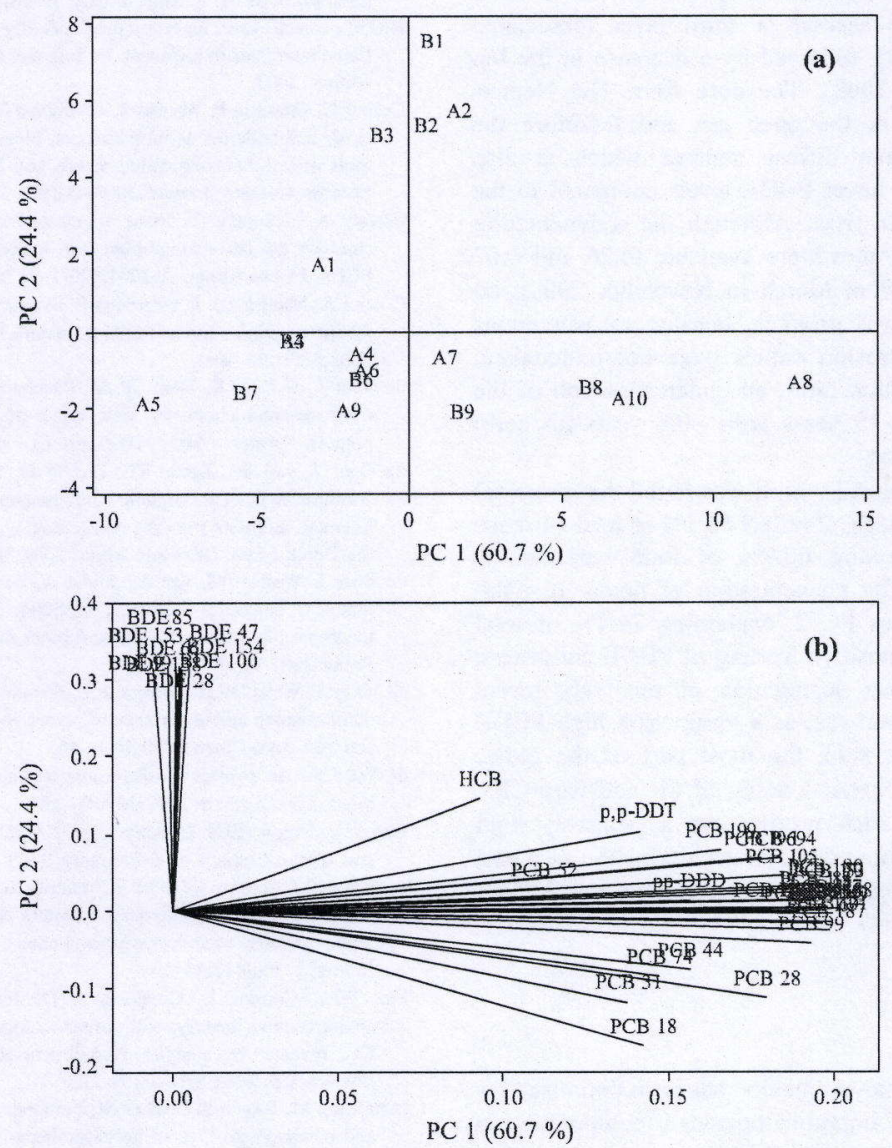

Fig. 5. Score plot (a) and loading plot (b) of PCA analysis based on concentrations of POPs (except of BDE 209) in two sediment cores from the Scheldt river. 
Due to high concentrations of BDE 209, an intensive use of technical deca-BDE is evident for the top layers (Table 4), while for tetra- to hexa-BDEs, similarities with the profile of Bromkal 70-5DE is pronounced for medium sediment cores. Compared to the technical penta-BDE mixture, the surface slices from both sediment cores are slightly enriched in BDE 153 , which can partly be due to a possible formation of hexa-BDEs by debromination of BDE 209.

Similar to what was observed in sediment cores from the Scheldt river (present study), BDE 209 was also the predominant PBDE congener in sediment cores from Wadden sea, The Netherlands and Drammenfjord, Norway (Zegers et al., 2003). The tri- to hexa-BDE congeners had also a technical penta-BDE mixture profile and their concentrations were 10-15 times lower than concentrations of BDE 209. While the cores from the Scheldt river showed a continuous increase in the PBDE concentrations in the top layers, the sediment cores from The Netherlands and Norway showed a peak in the PBDE concentrations in the second or third layer (associated with years 1994-1998), followed by a decrease in the top layer (Zegers et al., 2003). The core from The Netherlands was collected in the open sea and therefore the PBDE input was from diffuse sources which is also reflected in the much lower PBDE levels compared to the cores from the Scheldt river. Although the sedimentation rates at the collection sites were available $(0.26$ and 0.67 $\mathrm{cm} /$ month measured from March to November 2000), no dating of sediments was possible, because measurements of bioturbation and erosion values were not undertaken. Using only sedimentation rates, an underestimation of the age of the cores $(10-15$ years with -0.3 years $/ \mathrm{cm}$ core) would have been made.

Using PCA as statistical tool, it was found that principal components (PC) 1 and PC 2 reflect $85.1 \%$ of total variance (Fig. 5). PC1, explaining $60.7 \%$ of total variance, is significantly affected by concentration of penta- to octaCB congeners, whereas PC 2, explaining $24.4 \%$ of total variance, shows high positive loading of PBDE congeners. It can be seen a clear segregation of relatively recent deposed B1, B2, B3 and A2, as a group with high PBDE content. On the other side, the most part of the oldest sediment cores show higher loading of tri- and tetra-CBs. Possible reasons for such profiles are a relatively high contribution of anaerobic microbial dechlorination or a past use of technical mixtures containing lower chlorinated PCBs (Aroclor 1242 and 1254).

\section{Conclusions}

A simple and fast analysis method has been optimised for the determination of organohalogenated compounds in sediment cores. While the use of Soxhlet extraction in hot extraction mode allowed a substantial reduction of extrac- tion time (down to $2 \mathrm{~h}$ ), the use of $\mathrm{Cu}$ powder during extraction and clean-up eliminated the use of an additional step for sulphur removal. While concentrations of PCBs and DDTs in sediment samples from the Scheldt river were found to decline slightly in the last years, the concentrations of PBDEs have increased exponentially, in accordance with similar observations worldwide.

\section{Acknowledgements}

Adrian Covaci was financially supported by a GOA project of the University of Antwerp (2001).

\section{References}

Allchin C, Law R, Morris S. Polybrominated diphenylethers in sediments and biota downstream of potential sources in the UK. Environ Pollut 1999;105:197-207.

Baeyens W, van Eck B, Lambert C, Wollast R, Goeyens L. General description of the Scheldt estuary. Hydrobiologia 1998;366:1-14.

BROC project- draft report on the feasibility of certification of brominated flame retardants in sediment. In: Lohman M, van Leeuwen S, de Boer J, editors. 2003.

Coteur G, Gosselin P, Wantier P, Chambost-Manciet Y, Danis B, Pernet P, et al. Echinoderms as bioindicators, bioassays, and impact assessment tools of sediment-associated metals and PCBs in the North Sea. Arch Environ Contam Toxicol 2003;45:190-202.

Covaci A, Schepens P. Mass spectrometric detection for narrow-bore capillary gas chromatography: fast, selective and sensitive detection of PCBs. J Chromatogr, A 2001;923(1-2):287-93.

Covaci A, Manirakiza P, Schepens P. Evaluation of hot Soxhlet extraction for the determination of POPs from soil. Bull Environ Contam Toxicol 2002;68(1):97-103.

de Boer J, de Boer K, Boon JP. In: Paasivirta J, editor. The handbook of environmental chemistry, new types of persistent halogenated compounds. Springer-Verlag; 2000. pp. 61-95. ISBN 3-540-6583-6.

de Boer J, van der Zande TE, Pieters H, Ariese F, Schipper CA, van Bummelen $\mathrm{T}$, et al. Organic contaminants and trace metals in flounder liver and sediment from the Amsterdam and Rotterdam harbours and off the Dutch coast. J Environ Monit 2001;3:386-93.

de Boer J, Wester PG, van der Horst A, Leonards PEG. Polybrominated diphenyl ethers in influents, suspended matter, sediments, sewage treatment plant and effluents and biota from the Netherlands. Environ Pollut 2003;122:63-74.

de Voogt P, Wells DE, Reutergardh L, Brinkman UATh. Biological activity, determination and occurrence of planar, mono- and di-ortho PCBs. Int J Environ Anal Chem 1990;40:1-46.

de Wit CA. An overview of brominated flame retardants in the environment. Chemosphere 2002;46:583-624.

European Union (EU). Directive 2003/11/EC of the European Parliament and of the Council of 6 February 2003 amending for the 24th time Council Directive $76 / 769 / \mathrm{EEC}$ relating to restrictions on the marketing and use of certain dangerous substances and preparations (pentabromodiphenyl ether, octabromodiphenyl ether), http://europa.eu.int/. Official Journal L 2003;42:45-6.

Fox WM, Connor L, Copplestone D, Johnson MS, Leah RT. The contamination history with organochlorines of the Mersey estuary, UK, revealed by analysis of sediment cores from salt marshes. Mar Environ Res 2001;51(3):213-27.

Ikonomou M, Rayne S, Fischer M, Fernandez M, Cretney W. Occurrence and congener profiles of polybrominated diphenyl ethers (PBDEs) in environmental samples from coastal British Columbia, Canada. Chemosphere 2002;46:649-63. 
Isosaari $\mathrm{P}$, Pajunen $\mathrm{H}$, Vartiainen T. PCDD/PCDF and PCB history in dated sediments of a rural lake. Chemosphere 2002;47:575-83.

Jones KC, de Voogt P. Persistent organic pollutants (POPs): state of the science. Environ Pollut 1999;100:209-21.

Law RJ, Alaee M, Allchin CR, Boon JP, Lebeuf M, Lepom P, et al. Levels and trends of polybrominated diphenylethers and other brominated flame retardants in wildlife. Environ Int 2003;29(6):757-70.

NAWQA (National Water Quality Assessment Program). Organochlorine pesticides and PCBs in bed sediment and whole fish from United States rivers and streams, 1992-2001. Summary Statistics; Preliminary Results from Cycle I of NAWQA. http://ca.water.usgs.gov/pnsp/ oc_doc.html, 2003.

Pruell RJ, Rubinstein NI, Taplin BK, LiVolsi JA, Bowen RD. Accumulation of polychlorinated organic contaminants from sediment by benthic marine species. Arch Environ Contam Toxicol 1993;24:290-7.

Riis V, Babel W. Removal of sulphur interfering in the analysis of organochlorines by GC-ECD. Analyst 1999;124:1771-3.

Sjödin A, Jakobsson E, Kierkegaard A, Marsh G, Sellström U. GC identification and quantification of polybrominated diphenyl ethers in a commercial product, Bromkal 70-5DE. J Chromatogr, A 1998;822: $83-9$.

Smedes F, de Boer J. Determination of chlorobiphenyls in sedimentsanalytical methods. Trends Anal Chem 1997;16(9):503-17.
UNEP. Stockholm Convention: Master List of Actions: on the reduction and/or elimination of the releases of persistent organic pollutants, Fifth ed. Geneva, Switzerland: United Nations Environmental Programme; 2003.

Van Zoest R, Van Eck GTM. Historical input and behavior of HCB, PCBs and PAHs in 2 dated sediment cores from the Scheldt estuary, SW Netherlands. Mar Chem 1993;44(1):95-103.

Voorspoels S, Covaci A, Schepens P. Polybrominated diphenyl ethers in marine species from the Belgian North Sea and the Western Scheldt Estuary: levels, profiles, and distribution. Environ Sci Technol 2003; 37:4348-57.

Voorspoels S, Covaci A, Maervoet J, De Meester I, Schepens P. Distribution of $\mathrm{PCBs} / \mathrm{OCPs}$ in benthic organisms and fish from the North Sea Continental Shelf and Scheldt estuary. Mar Pollut Bull 2004; $49: 393-404$.

World Health Organization. Environmental health criteria 162: brominated diphenyl ethers. Geneva, Switzerland; 1994.

Zegers BN, Lewis WE, Booij K, Smittenberg RH, Boer W, de Boer J, et al. Levels of polybrominated diphenyl ether flame retardants in sediment cores from Western Europe. Environ Sci Technol 2003;37 $3803-7$ 